\title{
Plasma antioxidants and oxidative stress status in obese women: correlation with cardiopulmonary response
}

\author{
Dyg Mastura Adenan ${ }^{1}$, Zulkarnain Jaafar ${ }^{\text {Corresp., } 2}$, Jaime Jacqueline Jayapalan ${ }^{1}$, Azlina Abdul Aziz ${ }^{1}$ \\ 1 Department of Molecular Medicine, University of Malaya, Kuala Lumpur, Malaysia \\ 2 Department of Sports Medicine, University Malaya Medical Centre, Lembah Pantai, Kuala Lumpur, Malaysia \\ Corresponding Author: Zulkarnain Jaafar \\ Email address: zulkarnainj@um.edu.my
}

Introduction. A high body fat coupled with low cardiopulmonary fitness and an increase in oxidative stress has been connoted as contributing factors in developing cardiovascular comorbidities. This study aimed to investigate the correlation between antioxidants and oxidative stress status with cardiopulmonary responses in women of different body mass index (BMI).

Subjects and Methods. Eighty female adults were recruited and divided into three groups; normal weight $(n=23)$, overweight $(n=28)$ and obese $(n=29)$, according to their BMI. Blood samples were obtained prior to cardiopulmonary exercise testing. Plasma samples were separated by centrifugation and analysed for enzymatic antioxidant activity including catalase, glutathione peroxidase and superoxide dismutase. Non-enzymatic antioxidant activities were assessed using 2, 2'-azino-bis (3ethylbenzothiazoline-6-sulphonic acid) (ABTS) radical scavenging and ferric reducing ability of plasma (FRAP) assays. To evaluate the oxidative stress status of subjects, levels of reactive oxygen species and malondialdehyde, the by-product of lipid peroxidation, were measured. Cardiopulmonary responses were analysed using cardiopulmonary exercise testing (CPET) which involved 15 various parameters such as peak oxygen consumption, metabolic equivalents and respiratory exchange ratio.

Results. The obese group had significantly lower ABTS radical scavenging and FRAP activities than the normal weight group. A higher catalase activity was observed in the obese group than the normal weight group. Spearman's correlation showed an inverse relationship between catalase and peak oxygen consumption, while partial correlation analysis showed inverse correlations between superoxide dismutaseand respiratory frequency, ABTS activity and oxygen pulse, and between ABTS activity and cardiac output.

Conclusion. Our results demonstrate a lower cardiovascular fitness and antioxidant capacity in obese women; the higher catalase activity may be a compensatory mechanism. The negative correlations found between these two parameters may indicate the potential effect of antioxidants on the cardiopulmonary system and deserve further analysis in a larger population. Nevertheless, this study provides the basis for future studies to further explore the relationships between redox status and cardiopulmonary responses. This can potentially be used to predict future risk of developing diseases associated with oxidative stress, especially pulmonary and cardiovascular diseases. 
1 Plasma antioxidants and oxidative stress status in

2 obese women: correlation with cardiopulmonary

3 response

4

5

6

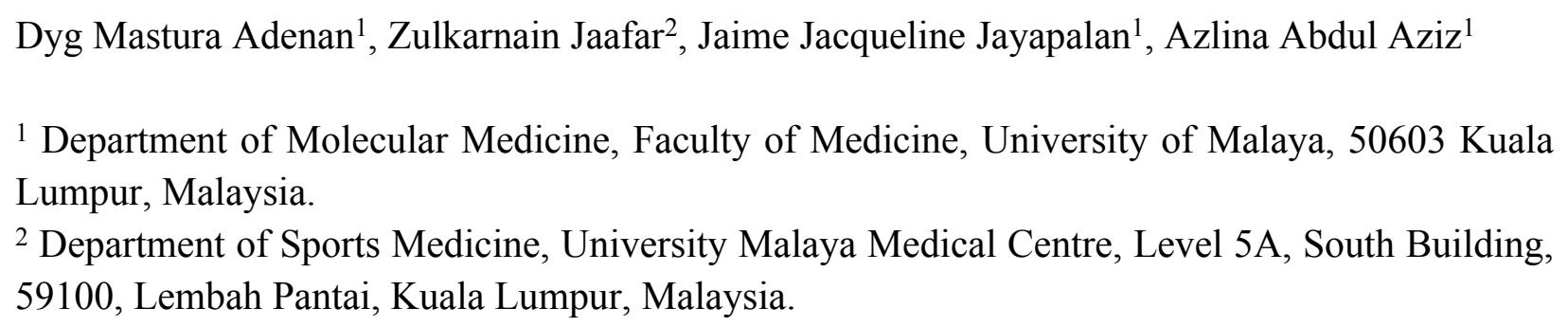

\section{Abstract}

Introduction. A high body fat coupled with low cardiopulmonary fitness and an increase in oxidative stress has been connoted as contributing factors in developing cardiovascular comorbidities. This study aimed to investigate the correlation between antioxidants and oxidative stress status with cardiopulmonary responses in women of different body mass index (BMI).

Subjects and Methods. Eighty female adults were recruited and divided into three groups; normal weight $(n=23)$, overweight $(n=28)$ and obese $(n=29)$, according to their BMI. Blood samples were obtained prior to cardiopulmonary exercise testing. Plasma samples were separated by centrifugation and analysed for enzymatic antioxidant activity including catalase, glutathione peroxidase and superoxide dismutase. Non-enzymatic antioxidant activities were assessed using 2, 2'-azino-bis (3-ethylbenzothiazoline-6-sulphonic acid) (ABTS) radical scavenging and ferric reducing ability of plasma (FRAP) assays. To evaluate the oxidative stress status of subjects, levels of reactive oxygen species and malondialdehyde, the by-product of lipid peroxidation, were measured. Cardiopulmonary responses were analysed using cardiopulmonary exercise testing (CPET) which involved 15 various parameters such as peak oxygen consumption, metabolic equivalents and respiratory exchange ratio.

Results. The obese group had significantly lower ABTS radical scavenging and FRAP activities than the normal weight group. A higher catalase activity was observed in the obese group than the normal weight group. Spearman's correlation showed an inverse relationship between catalase and peak oxygen consumption, while partial correlation analysis showed inverse correlations between superoxide dismutase and respiratory frequency, ABTS activity and oxygen pulse, and between ABTS activity and cardiac output. 
Conclusion. Our results demonstrate a lower cardiovascular fitness and antioxidant capacity in obese women; the higher catalase activity may be a compensatory mechanism. The negative correlations found between these two parameters may indicate the potential effect of antioxidants on the cardiopulmonary system and deserve further analysis in a larger population. Nevertheless, this study provides the basis for future studies to further explore the relationships between redox status and cardiopulmonary responses. This can potentially be used to predict future risk of developing diseases associated with oxidative stress, especially pulmonary and cardiovascular diseases.

Keywords. antioxidants, oxidative stress, cardiopulmonary exercise test, BMI, obese women

\section{Introduction}

Obesity is considered as a $21^{\text {st }}$-century epidemic worldwide (Rössner, 2002). Its prevalence is higher in female adults as opposed to male adults, and several sociocultural factors have been associated with the disparities of weight gain between genders (Kanter \& Caballero, 2012). Overweight and obesity are defined as exorbitant adipose tissue accumulation (Rocha \& Libby, 2009) that could contribute to the pathogenesis of metabolic diseases, cardiovascular diseases, pulmonary diseases and certain types of cancer (Sigh et al., 2017). The high incidence of overweight and obesity is associated with a sedentary lifestyle (Ekkekakis et al., 2016), in which low physical activity coupled with high consumption of energy-dense food over the needs of an individual would cause excess adipose tissue deposition in the body (Doucet et al., 1998).

High energy intake coupled with low energy expenditure causes the unused energy to be converted to and stored in the form of triglycerides in adipose tissues, either through an increase in adipocyte number (hyperplasia) or size (hypertrophy) (Jung \& Choi, 2014). Accumulated adipose tissues in obesity trigger many reactions including the release of pro-inflammatory cytokines such as interleukin-6 (IL-6) and tumour necrosis factor alpha (TNF- $\alpha$ ) (Kawasaki et al., 2012). In addition, infiltration of immune cells into adipose tissues can lead to elevated generation of reactive oxygen species (ROS) (Appari, Channon \& McNeill, 2018). At a low or moderate level, ROS act as secondary messengers in cell signalling cascades (Kietzmann \& Görlach, 2005). However, an imbalance between the production of ROS and the ability of antioxidants to counteract these species, in favour of the former, can lead to oxidative stress (Aruoma, 1998). This can cause damage to important cellular structures such as membranes, proteins, lipids and nucleic acids (Ceriello \& Motz, 2004). Increased oxidative stress in obesity is reported as one of the mechanisms for the pathogenesis of several chronic diseases such as cardiovascular diseases, diabetes and cancer (Pizzino et al., 2017).

In humans, redox status can be evaluated by measuring antioxidant activities and markers of oxidative stress. Antioxidant activities can be determined by measuring reducing activities, radical scavenging or chelating capacities of antioxidants. On the other hand, oxidative stress can be 
evaluated by measuring levels of ROS, activities of antioxidant enzymes as well as by-products of oxidative damage such as malondialdehyde and 8-hydroxy-2'-deoxyguanosine (8-OHdG) (Ho et al., 2013).

Obese patients have a high level of fat mass (FM) and fat-free mass (FFM), which contribute to a higher circulating blood volume (Van der Kooy et al., 1992). High FM and FFM can augment the left ventricular stroke volume, and burden the heart, which may eventually lead to heart failure (Collis et al., 2001). Obese individuals may also have abnormal lung function as a result of increased weight, which in the long run, could lead to cardiovascular diseases such as heart failure and stroke (Poirier et al., 2006). Cardiopulmonary fitness that is assessed via exercise test provides an evaluation of overall exercise responses involving pulmonary, cardiovascular and skeletal muscle system during exercise and at rest (Albouaini et al., 2007).

At present, there is still a lack of information on the association between antioxidants and oxidative stress status with cardiopulmonary fitness and body composition in humans, more so in females. Information on the association between redox status and cardiopulmonary fitness can be potentially used in predicting future risk of developing diseases associated with oxidative stress, especially pulmonary and cardiovascular diseases. Therefore, this study aimed to investigate the correlation between antioxidants and oxidative stress status with cardiopulmonary responses in women of different body mass index (BMI).

\section{Materials \& Methods}

\section{Study Participants}

All procedures involving human subjects complied with the Declaration of Helsinki 1975, as revised in 1983. The study protocol was approved by the Medical Research Ethics Committee of University Malaya Medical Centre (UMMC), Kuala Lumpur, Malaysia (reference number: 2017417-5141). Study participants were recruited among UMMC staff and students. Written informed consent was obtained from each volunteer. Female adults, aged 19 - 55 years old with any weight status except underweight were recruited. Exclusion criteria were subjects who smoke, subjects with any cardiovascular disease at any point of time, respiratory problems either restrictive or obstructive, musculoskeletal disabilities that could limit from performing exercise testing, and subjects with any medical conditions such as diabetes mellitus, epilepsy, hypertension, renal or thyroid problems.

\section{Anthropometric Measurements and Subjects' Classification}

For anthropometry measurements, we followed the anthropometry procedures manual guidelines of The National Health and Nutrition Examination Survey (NHANES). Subject's height was measured using Detecto ProDoc series physician scales (Detecto, China). Body weight and composition were measured using Bio-Impedance Analysis (InBody 270, USA) following the manufacturer's protocol. BMI is calculated based on the weight of an individual in kilogram 
120

121

122

123

124

125

126

127

128

129

130

131

132

133

134

135

136

137

138

139

140

141

142

143

144

145

146

147

148

149

150

151

152

153

154

155

156

157

158

159

divided by the square of height in meter $\left(B M I=\mathrm{kg} / \mathrm{m}^{2}\right)$. The subjects were classified into three groups according to their BMI (Lim et al., 2017): Normal weight $\left(18.5-22.9 \mathrm{~kg} / \mathrm{m}^{2}\right)$, overweight $\left(23-24.9 \mathrm{~kg} / \mathrm{m}^{2}\right)$ and obese $\left(\geq 25 \mathrm{~kg} / \mathrm{m}^{2}\right)$.

\section{Sample Collections}

Blood sampling for oxidative stress and antioxidants markers were done prior to the CPET. The blood samples were collected from April to July 2018. Three millilitre blood was collected in K2EDTA tubes (BD, USA). The samples were centrifuged at $2246 \mathrm{x}$ g for 15 minutes at $4^{\circ} \mathrm{C}$. Plasma were separated, transferred to Eppendorf tubes and stored at $-80^{\circ} \mathrm{C}$ until further analyses.

\section{Biochemical analyses}

\section{ABTS radical scavenging activity}

2, 2'-azino-bis (3-ethylbenzothiazoline-6-sulphonic acid) (ABTS) radical scavenging activity in plasma was measured as previously described (Re et al., 1999). ABTS radicals were pre-generated by mixing $7 \mathrm{mM}$ ABTS and $2.45 \mathrm{mM}$ potassium persulfate in double-distilled water. The stock radical solution was incubated in the dark for approximately 16 hours at room temperature. Absorbance of the stock solution was adjusted to $0.7 \pm 0.02$ at $734 \mathrm{~nm}$ and served as the working solution. Phosphate buffer saline (PBS, pH 7.4) was used to dilute the stock solution. Five $\mu \mathrm{L}$ of plasma was added to $200 \mu \mathrm{L}$ of ABTS solution in a 96-well plate and incubated for 6 minutes and absorbance was taken at $734 \mathrm{~nm}$ using a spectrophotometer (Spectramax M3, USA). A standard curve was constructed using Trolox $(0-2.4 \mathrm{mM})$. All analyses were performed in triplicate. The final results were expressed as Trolox equivalent antioxidant capacity (TEAC) value.

\section{Ferric reducing ability plasma (FRAP)}

The ferric reducing ability of plasma was estimated as previously described (Benzie \& Strain, 1996). FRAP reagent was prepared by mixing $25 \mathrm{~mL}$ acetate buffer (300 mM, pH 3.6), $2.5 \mathrm{~mL} \mathrm{2,}$ 4, 6-tripyridyl-s-triazine (TPTZ) solution (10 mM TPTZ in $40 \mathrm{mM} \mathrm{HCl}$ ), and $2.5 \mathrm{~mL} \mathrm{FeCl}_{3} \cdot 6 \mathrm{H}_{2} \mathrm{O}$ solution $(20 \mathrm{mM})$. Briefly, $10 \mu \mathrm{L}$ plasma was added to $40 \mu \mathrm{L}$ double-distilled water. Then, 200 $\mu \mathrm{L}$ of FRAP reagent (warmed at $37^{\circ} \mathrm{C}$ ) was added to the sample and incubated for 8 minutes at $37^{\circ} \mathrm{C}$. The absorbance readings were taken at $600 \mathrm{~nm}$ against the blank. All analyses were performed in triplicate. The final results were expressed as $\mu \mathrm{mol} / \mathrm{L} \mathrm{FeSO}_{4}$.

\section{Reactive oxygen species (ROS)}

The fluorescence-based probe dichlorodihydrofluorescein diacetate (DCFH-DA) was used to detect for the presence of ROS (Dikalov, Griendling \& Harrison, 2007). Briefly, $5 \mu \mathrm{L}$ plasma and $100 \mu \mathrm{L}$ of DCFH-DA reagent were added into a 96-black well plate. The mixture was incubated in the dark for 30 minutes at room temperature. The fluorescence readings were captured with excitation and emission wavelength of $485 \mathrm{~nm}$ and $530 \mathrm{~nm}$, respectively on a fluorescence spectrophotometer (Spectramax M3, USA). All analyses were performed in triplicate. The final results were expressed as relative fluorescence unit (RFU). 
160

161

162

163

164

165

166

167

168

169

170

171

172

173

174

175

176

177

178

179

180

181

182

183

184

185

186

187

188

189

190

191

192

193

194

195

196

197

198

199

\section{Lipid peroxidation activity}

Thiobarbituric acid reactive substances (TBARS) assay was used to evaluate lipid peroxidation in the plasma samples (Ramli et al., 2017). Malondialdehyde (MDA), a by-product of lipid peroxidation in the sample will react with thiobarbituric acid to produce pink colored products. TBARS reagent was prepared by mixing $0.3 \mathrm{~g}$ TBA, $12 \mathrm{~mL}$ trichloroacetic acid and $1.04 \mathrm{~mL}$ of $70 \%$ perchloric acid in $80 \mathrm{~mL}$ double-distilled water. Fifty microliters of plasma samples and 250 $\mu \mathrm{L}$ of TBARS reagent were mixed together and heated for 30 minutes at $90^{\circ} \mathrm{C}$. Then, the mixture was left to cool on ice and subjected to centrifugation at $834 \mathrm{rpm}$ at $25^{\circ} \mathrm{C}$ for 10 minutes. Fifty microliters of the mixture were added into a 96-well plate and the absorbance reading was taken at $532 \mathrm{~nm}$. 1, 1, 3, 3-tetraethoxypropane (TEP) was used as standard and analysed as above. All analyses were performed in triplicate. The final results were expressed as micromoles per litre $(\mu \mathrm{mol} / \mathrm{L})$.

\section{Catalase (CAT) activity}

CAT activity was determined as previously described (Góth, 1991) with slight modifications (Hadwan \& Abed, 2016). Ten microliters of plasma were incubated with $100 \mu \mathrm{L}$ of substrate (65 $\mu \mathrm{M}$ hydrogen peroxide in $60 \mathrm{mM}$ sodium-potassium phosphate buffer, $\mathrm{pH} 7.4$ ) at $37^{\circ} \mathrm{C}$ for 3 minutes. The reaction was stopped by adding $400 \mu \mathrm{L}$ ammonium molybdate $(32.4 \mathrm{mM})$. The absorbance of the yellowish complex was determined at $397 \mathrm{~nm}$. All analyses were performed in triplicate. The final results were expressed as enzyme unit (U).

\section{Glutathione peroxidase (GPx) activity}

GPx enzyme activity was determined using a colorimetric assay kit (Cayman Chemical, USA) according to the manufacturer's protocol. GPx activity was estimated indirectly by a coupled reaction with glutathione reductase and NADPH. The oxidation of NADPH to NADP+ caused decrease in absorbance at $340 \mathrm{~nm}$. The rate of decrease in absorbance at $340 \mathrm{~nm}$ is directly proportional to the GPx activity in the samples. Briefly, $100 \mu \mathrm{L}$ of assay buffer, $50 \mu \mathrm{L}$ of cosubstrate mixture and $20 \mu \mathrm{L}$ of sample were added into a 96-well plate. The reaction was initiated by adding $20 \mu \mathrm{L}$ cumene hydroperoxide. The absorbance was read once every minute at $340 \mathrm{~nm}$ to obtain at least five time points. All analyses were performed in triplicate. The final results were expressed as nanomoles per minute per milliliter (nmol/min/ml).

\section{Superoxide dismutase (SOD) activity}

SOD activity was determined using a colorimetric assay kit (Cayman Chemical, USA), according to the manufacturer's protocol. The SOD assay kit used tetrazolium salt for the detection of superoxide radicals generated by xanthine oxidase and hypoxanthine. Briefly, $200 \mu \mathrm{L}$ diluted radical detector and $10 \mu \mathrm{L}$ sample were added into the wells. The reaction was initiated by adding $20 \mu \mathrm{L}$ diluted xanthine oxidase to the wells. The mixture was incubated for 30 minutes at room temperature and absorbance reading was taken at $450 \mathrm{~nm}$. All analyses were performed in 
200 triplicate. The final results were expressed as unit per millilitre $(\mathrm{U} / \mathrm{ml})$ whereby one unit of SOD 201 is defined as the amount of enzyme needed to exhibit $50 \%$ dismutation of the superoxide radicals.

202

203

204

205

206

207

208

209

210

211

212

213

214

215

216

217

218

219

220

221

222

223

224

225

226

227

228

229

230

231

232

233

234

235

236

237

238

239

\section{Cardiopulmonary exercise testing (CPET)}

CPET was conducted at the human performance lab, Department of Sports Medicine, UMMC, Kuala Lumpur, Malaysia. Stationary cycle ergometer (Cosmed, Italy) was used, and the test was performed according to The Ramp protocol (Takken et al., 2009). The Ramp protocol involved a gradual increase of work rate in a stepwise pattern over time. Firstly, the subjects were required to warm-up on the unloaded pedalling for $1-3$ minutes. The work rate was increased by 10 watts for each minute. Verbal encouragement was given to the subjects to exercise until they reached volitional exhaustion. On average, the test lasted for $8-12$ minutes and the exercise testing provides useful physiological information including exercise work, metabolic response, metabolic gas exchange, ventilatory response, cardiovascular response, and pulmonary gas exchange. Below were formulae of some of the parameters measured in CPET:

Peak oxygen consumption $=($ Heart rate $\mathrm{X}$ Stroke volume $) \mathrm{X}$ [Arteriovenous oxygen difference] Oxygen pulse $=$ Oxygen uptake $\div$ Heart rate

Metabolic equivalents $=[1.8($ Work rate $) \div$ Body mass $]+3.5+3.5$

\section{Statistical analyses}

The sample size was calculated using G-Power version 3.1.9.2. The G-Power indicated that a minimum sample of 66 produced $95 \%$ confident level with effect size of $f=0.40, \alpha=0.05$ and $1-\beta$ $=0.80$. Mean and standard deviation of maximum oxygen consumption $\left(\mathrm{VO}_{2} \mathrm{max}\right)$ which is the indicator of fitness level were used based on study by Pandey et al. (2014). The calculated sample size plus 20\% dropout is 80 subjects. The Statistical Package for Social Sciences (SPSS) version 22.0 (IBM, NY, USA) was used to perform the statistical analyses. The Kolmogrov-Smirnov test was used to determine the distribution of the data. For variables that were normally distributed, one-way analysis of variances (ANOVA) was used to compare the mean differences of antioxidants and oxidative stress status and CPET parameters among the groups. The data were presented as mean \pm standard deviation. In the post-hoc analyses, multiple comparisons of specific sample pairs were done. The Tukey post-hoc test was used when equal variances were assumed and Dunnett's T3 post-hoc test when equal variances were not assumed. The assumption was verified based on Levene's test of homogeneity. Correlation of the normally distributed variables were tested using Pearson's test and the partial correlation analysis was further performed to control for the effect of age on the redox and cardiopulmonary responses parameters. For skewed variables, Kruskal-Wallis test was used to compare the non-parametric variables among the groups. The non-normally distributed data were presented as median (25th, 75th percentiles). Spearman's test was used to determine the non-parametric relationship between the variables. A $p$-value less than 0.05 was considered significant.

\section{Results}




\section{Study subjects}

The mean BMI for the study population was $25.94 \pm 4.87 \mathrm{~kg} / \mathrm{m}^{2}$. Table 1 shows the descriptive characteristics of the study subjects. The subjects' height did not differ significantly among the three BMI groups: Normal weight (NW), overweight (OW) and obese (OB) $(p=0.89)$. The waisthip ratio was significantly different between the OB-NW groups and OW-NW groups $(p<0.001)$. Percentage body fat, body fat mass and skeletal muscle mass were significantly different between the OB-NW groups, OB-OW groups and OW-NW groups $(p<0.001)$. The highest value in the aforementioned parameters was noted in the OB group.

Insert Table 1: Characteristics of the study subjects.

\section{Biochemical analyses}

The blood plasma was tested for antioxidant activities and oxidative stress status. The ABTS radical scavenging activity was significantly lower in $\mathrm{OB}[\mathrm{F}=7.314, \mathrm{p}=0.001,95 \% \mathrm{CI}[-0.54$, $-0.02]]$ and $\mathrm{OW}[\mathrm{F}=7.314, \mathrm{p}=0.001,95 \% \mathrm{CI}[-0.67,-0.15]]$ groups compared to the NW group (Fig.1 (a)). No significant difference was observed between the OB and OW groups $(p>0.05)$. FRAP activity was significantly lower in the OB group compared to NW $[\mathrm{F}=6.382, \mathrm{p}=0.003$, 95\% CI [-270.68, -17.99]] and OW [F $=6.382, \mathrm{p}=0.003,95 \% \mathrm{CI}[-288.01,-46.23]]$ groups (Fig.1 (b)). The OW and NW groups did not differ significantly in the FRAP activity $(p>0.05)$. No significant differences in the ROS and MDA levels were observed among the different BMI groups $(p>0.05)$ (Fig. $1(\mathrm{c}, \mathrm{d})$ ). CAT activity was significantly higher in the OB $[\mathrm{F}=4.609, \mathrm{p}=$ $0.013,95 \%[0.70,4.83]]$ and $\mathrm{OW}[\mathrm{F}=4.609, \mathrm{p}=0.013,95 \%[0.20,4.06]]$ groups compared to the NW group (Fig.1 (e)). On the contrary, GPx and SOD activities did not differ significantly among the different BMI groups $(p>0.05)$ (Fig.1 (f, g)).

Insert Figure 1: Biochemical analyses of plasma.

\section{CPET analyses}

CPET analyses were done to determine the cardiac, pulmonary and respiratory gas exchange performances. Table 2 shows all the CPET analyses. Peak oxygen consumption $\left(\mathrm{VO}_{2}\right.$ peak) was observed to be significantly lower in OB versus NW groups and OB versus OW groups $(p<0.001)$, however, no significant difference was seen between OW and NW groups $(p>0.05)$. A similar significant pattern was also observed in the metabolic equivalents (METs) parameter between OB versus NW groups and OB versus OW groups $(p<0.001)$. There was a decreasing trend in peak heart rate $(p=0.04)$ with increased BMI, but no significant difference was observed among the different BMI groups. On the other hand, oxygen pulse was found to be significantly higher in OB compared to NW groups and also in OW compared to NW groups $(p<0.001)$. The remaining parameters measured during CPET showed no significant differences among the different BMI groups of subjects $(p>0.05)$. 
280

281

282

283

284

285

286

287

288

289

290

291

292

293

294

295

296

297

298

299

300

301

302

303

304

305

306

307

308

309

310

311

312

313

314

315

316

317

318

319

Insert Table 2: Cardiopulmonary exercise testing (CPET) analyses.

\section{Correlation analyses between biochemical and CPET parameters}

Data from the antioxidant activities and oxidative stress parameters, together with the CPET parameters, were analysed to determine their relationships. Table 3 shows the correlation analyses between the biochemical and CPET parameters. MDA was found to be inversely correlated with exercise duration $(\mathrm{r}=-0.263)$ while CAT activity demonstrated an inverse correlation with peak oxygen consumption $(\mathrm{r}=-0.251)$. ABTS radical scavenging activity was inversely correlated with both oxygen pulse $(r=-0.253)$ and cardiac output $(r=-0.252)$. The remaining parameters did not show any significant correlation $(p>0.05)$.

Insert Table 3: Correlation analyses between biochemical and CPET parameters.

Due to the large age gap of the subjects, partial correlation analysis was also performed to control for the effect of age on the various parameters measured in the study. Table 4 shows the Pearson's partial correlation analyses between the biochemical and CPET parameters. Similar to Table 3, an inverse correlation was seen between ABTS radical scavenging activity with both oxygen pulse $(\mathrm{r}=-0.26)$ and cardiac output $(\mathrm{r}=-0.25)$. On the other hand, SOD activity showed an inverse correlation with respiratory frequency $(\mathrm{r}=-0.23)$, a correlation not previously observed. The remaining parameters did not demonstrate any significant differences $(p>0.05)$.

Insert Table 4: Pearson's partial correlation analyses between biochemical and CPET parameters

\section{Discussion}

Obesity is a risk factor for developing cardiovascular diseases such as heart and coronary artery disease (Yudkin et al., 2000; Van Gaal, Mertens \& De Block, 2006). At the meantime, oxidative stress and exercise capacity are the parameters that could be used to predict future cardiovascular risk in an individual (Migliore et al., 2005; Myers et al., 2015). Yet, the majority of studies have often analysed antioxidant activities, oxidative stress and cardiopulmonary responses separately and have not assessed their correlation. Thus, there is a lack of data on the actual relationship between these parameters. To overcome these limitations, our study analysed possible correlation between these parameters.

Antioxidants play important protective role against excessive production of free radicals, through scavenging or inhibiting their activities (Nimse \& Pal, 2015). Plasma contains numerous low molecular weight antioxidants such as ascorbic acid, tocopherol, and uric acid (Chevion et al., 1997), which can be measured through several antioxidant assays. The ABTS assay measures the ability of antioxidants in plasma to scavenge ABTS radicals while the FRAP assay measures the capacity of antioxidants to reduce ferric ions (Dasgupta \& Klein, 2014). In this study, the data shows that the ABTS scavenging activity and FRAP activity are lower in obese (OB) than the 
320

321

322

323

324

325

326

327

328

329

330

331

332

333

334

335

336

337

338

339

340

341

342

343

344

345

346

347

348

349

350

351

352

353

354

355

356

357

358

359

normal weight (NW) group. This implies the possibility of body fat mass influencing antioxidant status. Several studies have been conducted on the effects of body fat on antioxidants and oxidative stress status (Savini et al., 2013; Lubrano et al., 2015; Lechuga-Sancho et al., 2018). While majority of the studies demonstrated that high body fat was correlated with low antioxidant activities and high oxidative stress (Amirkhizi et al., 2010; Hermsdorff et al., 2011; Jankovic et al., 2014), some studies reported the opposite effect or no difference and these may be due to the dietary antioxidants intake of individuals (Brown et al., 2009; Amaya-Villalva et al., 2015; Wang \& Hui 2015; Colak et al, 2019). However, results from our study seem to agree with previous reports on the inverse association of body fat with antioxidant status. The reduced antioxidant activities in the OB group could also be due to other factors such as dietary habits. A study had reported that women who followed a high quality diet, indicative of high intake of fruit and vegetables and low amounts of fat, were more likely to have lower BMI (Boynton et al., 2008). In addition, antioxidants may be mobilised elsewhere in the body to combat oxidative stress (Clarkson \& Thompson, 2000; Abdali, Samson \& Grover, 2015). However, some studies show that even with high dietary consumption of antioxidants-rich food, obese individuals still demonstrated deficiency of micronutrients (Via, 2000; Soare et al., 2014).

In addition to the low molecular weight antioxidant molecules, antioxidant enzymes are also protective against oxidative damage (Jeeva et al., 2015). The present data shows higher CAT activity in the OB group than the NW group. The low antioxidant activities and high CAT activity in the OB group are suggestive of the presence of oxidative stress, as reported by several publications (Tinahones et al., 2008; Bausenwein et al., 2009; Zhang, Liu \& Zong, 2016). CAT is a tetrameric protein and is predominantly found in peroxisomes. It catalyses the conversion of hydrogen peroxide to hydrogen and water (Ighodaro \& Akinloy, 2018). The increased CAT activity could be a compensatory mechanism to overcome the increased hydrogen peroxide content. Our finding was in line with the study by Rindler who reported a significant increase in CAT activity in mouse fed with a high-fat diet, for 2 to 30 weeks (Rindler et al., 2013). Indeed, overexpression of CAT has been shown to be beneficial in preventing oxidative damage (Awad, Aldosari \& Abid, 2018).

In this study, determination of oxidative damage was done by measuring levels of MDA and ROS in plasma. Results from the study demonstrate no significant differences in MDA and ROS levels among the different BMI groups. This implies that body fat does not contribute to the oxidative stress state. However, based on the findings of similar studies, the levels of MDA and ROS were reported to be significantly higher in the high BMI group (Yesilbursa et al., 2004; Sankhla et al., 2012; An et al., 2018). We speculated that the lack of significant differences in the oxidative stress parameters of the OB group, despite reduced antioxidant activities, could be due to the removal of the radicals by the increased CAT activity. It is also possible that changes in the levels of ROS and MDA in the OB group were too little that it could not be detected by the assays. 
360

361

362

363

364

365

366

367

368

369

370

371

372

373

374

375

376

377

378

379

380

381

382

383

384

385

386

387

388

389

390

391

392

393

394

395

396

397

398

Disease development arises as a result of abnormal interactions among several systems. During an incremental exercise testing (CPET), the assessment of ventilation and volume of oxygen uptake and exhaled carbon dioxide can provide comprehensive data on several body systems simultaneously, namely cardiac, respiratory, haematological, and musculoskeletal systems. The present study shows several significant findings of CPET parameters among the different BMI groups. We found that $\mathrm{VO}_{2}$ peak was significantly reduced in the $\mathrm{OB}$ group; $\mathrm{VO}_{2}$ peak is the highest attainable oxygen uptake at which the work parameters plateau, and it allows the determination of aerobic exercise capacity of an individual. Similar to our study, several studies have also demonstrated lower $\mathrm{VO}_{2}$ peak in OB than NW subjects (Miller et al., 2012; Shim et al., 2013; Bunsawat et al., 2017). The reduced $\mathrm{VO}_{2}$ peak point toward reduced exercise capacity, which may be caused by the gas exchange, cardiac, pulmonary, muscular, or effort limitations. A study conducted by Green et al., (2018) found that increasing BMI is associated with declined responses of $\mathrm{VO}_{2}$ peak and leg vascular conductance during cycling and isolated limb exercise. The reduction of $\mathrm{VO}_{2}$ peak in the $\mathrm{OB}$ group may be caused by decreased vasodilation in contracting muscles during exercise. Also, changes in lipid profiles together with weight gain may also affect vascular dynamics during muscle contraction leading to these findings (Steinberg et al., 1997; Clerk, Rattigan \& Clark, 2002; Steinberg et al., 2002).

Oxygen uptake increases as work increases, and our study shows that the cardiac output did not differ significantly among the BMI groups, and this may imply that cardiac output does not significantly contribute to the reduced $\mathrm{VO}_{2}$ peak in $\mathrm{OB}$ individuals in this study. The present study finds that MET was significantly lower in OB than NW subjects. MET relates to the individual's rate of oxygen uptake for a given work activity, and it dictates the functional capacity of an individual (Ainsworth et al., 2011). Oxygen is needed to fuel muscle contraction; thus, lower efficiency of energy expenditure during work resulted in poorer functional capacity. The lower MET in the OB group could be caused by the lower percentage of muscle mass (normalized to body weight) that is crucial for physical performance. Moreover, our study demonstrates a decreasing trend in the peak heart rate with increased BMI. This finding is supported by a study conducted by Loftin et al., (2003) which also found that peak heart rate was lower in young OB female compared to the NW group. Strandheim et al., (2015) also reported that obesity and obesity-associated metabolic changes influenced both resting and peak heart rate during exercise. The deposition of adipose tissues, particularly in the cardiac muscles may hinder the cardiac function and exert unfavourable burdens to the heart (Cole et al., 2011). In addition, oxygen pulse, which represents the amount of oxygen consumed per heart rate $\left(\mathrm{VO}_{2} / \mathrm{HR}\right)$ was higher in the $\mathrm{OB}$ and OW groups compared to the NW group. The increased oxygen pulse detected in $\mathrm{OB}$ and $\mathrm{OW}$ subjects in this study likely contributed to the increased cardiac output and stroke volume (Datta, Normandin \& ZuWallack, 2015). Laukkannen et al., (2006) suggested that oxygen pulse value can be used to predict the risk of coronary heart disease. 
399

400

401

402

403

404

405

406

407

408

409

410

411

412

413

414

415

416

417

418

419

420

421

422

423

424

425

426

427

428

429

430

431

432

433

434

435

436

437

438

With regards to the correlation between redox status and cardiopulmonary responses, our present study finds weak inverse correlations between $\mathrm{CAT}$ and $\mathrm{VO}_{2}$ peak. In response to the oxidative stress state, CAT activity would be increased to maintain the body's redox equilibrium, and likewise in this study we found that low exercise capacity level causes an elevation of the CAT activity in the OB subjects. Thus, the inverse correlation indicates a potential protective effect of exercise on prevention of lipid peroxidation. Interestingly, Lubkowska et al. in their study found that CAT activity could be reduced by engaging in regular moderate aerobic activity. (Lubkowska et al., 2015).

After controlling the age, we found that SOD has weak inverse correlation with respiratory frequency, and ABTS activity has weak inverse correlations with oxygen pulse and cardiac output. Obesity has a profound effect on the respiratory physiology (Parameswaran, Todd \& Soth, 2006) and it significantly affects respiratory function by decreasing lung volume, leading to increase in respiratory effort, oxygen consumption, and respiratory energy expenditure (Littleton, 2012; Mafort et al., 2016). Higher respiratory frequency may further increase ROS production through electron transport chain reaction (Salin et al., 2015). Hence, SOD activity should be increased in order to compensate for the high ROS. In our study, we found a weak negative correlation between SOD activity and respiratory frequency, which means in high ROS state, the SOD activity was low. A few studies have reported that SOD activity and zinc level were markedly low among obese individuals (Abdallah \& Samman, 1993; Torkanlou et al., 2016). Zinc is one of the cofactors of SOD, and it is possible that dietary zinc intake has an influence on SOD activity (Olechnowicz et al., 2017). In view of these, obese individuals may benefit from consuming food rich in zinc in order to increase their SOD activity and subsequently protect themselves against high ROS.

The increase in body mass in the OB individual leads to higher metabolic demand, increase oxygen requirements by the body, and increase adipose tissue perfusion, which subsequently leads to an increase in blood volume and augmentation of the cardiac output (Cepeda-Lopez et al., 2019). However, as a result of physical inactivity, the cardiovascular system develops an autonomic dysfunction (Csige et al., 2018; Williams et al., 2019) which leads to a decrease in the heart rate and heart rate peak, and as a compensatory mechanism, the cardiovascular system increases its stroke volume and oxygen pulse. Prolonged condition may lead to an enlargement of the heart called cardiomegaly (Ebong et al., 2014). Few studies have suggested that cardiomegaly is associated with a higher risk of sudden cardiac death in obese subjects (Abel et al., 2010; Tavora et al., 2012). The high oxygen consumption in OB individuals may lead to elevated rate of electron transport chain reaction, which subsequently produces a higher level of ROS in the body (Salin et al., 2015) meanwhile low ABTS radical scavenging activity may indicate the inability of antioxidant molecules to protect against oxidative stress in the OB group.

\section{Conclusions}


439

440

441

442

443

444

445

446

447

448

449

450

451

452

453

454

455

456

457

458

459

460

461

462

463

464

465

466

467

468

469

470

471

472

473

474

475

In conclusion, obese women exhibited reduced cardiopulmonary fitness and antioxidant capacity, while catalase was increased, possibly as a compensatory mechanism. The negative correlations found between some antioxidants and cardiopulmonary response parameters indicate that antioxidants may affect the cardiopulmonary system and deserve further investigation, taking into consideration the effect of levels of physical activity, history of diet, supplement intake, the effect of hormones and duration of obesity. Nevertheless, this cross-sectional data provides the basis for future studies to further explore the relationships between redox status and cardiopulmonary responses parameters. This could predict future risk of developing diseases associated with oxidative stress, especially cardiopulmonary and cardiovascular diseases.

\section{Acknowledgements}

We are grateful to all the subjects for their participation. The authors declare that there is no conflict of interest.

\section{References}

Abdali D, Samson SE, Grover AK. 2015. How effective are antioxidant supplements in obesity and diabetes?. Medical Principles and Practice 24:201-215. DOI: 10.1159/000375305

Abdallah SM, Samman S. 1993. The effect of increasing dietary zinc on the activity of superoxide dismutase and zinc concentration in erythrocytes of healthy female subjects. European Journal of Clinical Nutrition 47:327-332. PMID: 8319668

Abel ED, Litwin SE, Sweeney G. 2008. Cardiac remodelling in obesity. Physiology Reviews 88:389-419. DOI: 10.1152/physrev.00017.2007

Ainsworth BE, Haskell WL, Herrmann SD, Meckes N, Bassett Jr DR, Tudor-Locke C, Greer JL, Vezina J, Whitt-Glover MC, Leon AS. 2011. 2011 Compendium of physical activities: A second update of codes and MET values. Medicine \& Science in Sports \& Exercise 43:1575-1581.

DOI: 10.1249/MSS.0b013e31821ece12

Albouaini K, Egred M, Alahmar A, Wright DJ. 2007. Cardiopulmonary exercise testing and its application. Postgraduate Medical Journal 83:675-682. DOI: 10.1136/hrt.2007.121558

Amaya-Villalva MF, González-Aguilar G, Rouzaud-Sández O, Gorinstein S, Astiazarán-García H, Robles-Sánchez M. 2015. Obesity-related indicators and their relationship with serum antioxidant activity levels in Mexican adults. Nutricion hospitalaria 31:1989-1995.

DOI: $10.3305 / \mathrm{nh} .2015 .31 .5 .8524$. 
477 Amirkhizi F, Siassi F, Djalali M, Foroushini AR.2010. Evaluation of oxidative stress and total

478 antioxidant capacity in women with general and abdominal adiposity. Obesity Research \& Clinical 479 Practice 4:e209-e216. DOI: 10.1016/j.orcp.2010.02.003

480

An H, Du X, Huang X, Qi L, Jia Q, Yin G, Xiao C, Huang XF, Ning Y, Cassidy RM, Wang L, Soares JC, Zhang XY. 2018. Obesity, altered oxidative stress, and clinical correlates in chronic 483 schizophrenia patients. Translational Psychiatry 8:1-7. DOI: 10.1038/s41398-018-0303-7

484

485

486

Appari M, Channon KM, McNeill E. 2018. Metabolic regulation of adipose tissue macrophage function in obesity and diabetes. Antioxidants \& Redox Signaling 29:297-312.

487

DOI: $10.1089 /$ ars.2017.7060

488

Aruoma OI. 1998. Free radicals, oxidative stress, and antioxidants in human health and disease. 490 Journal of the American Oil Chemists' Society 75:199-212. DOI: 10.1007/s11746-998-0032-9

491

492

Awad MA, Aldosari SR, Abid MR. 2018. Genetic alterations in oxidant and anti-oxidant enzymes 493 in the vascular system. Frontiers in Cardiovascular Medicine 5:107.

494

DOI: $10.3389 /$ fcvm.2018.00107

495

496

497

Bausenwein J, Serke H, Eberle K, Hirrlinger J, Jogschies P, Hmeidan FA, Blumenauer V, SpanelBorowski K. 2009. Elevated levels of oxidized low-density lipoprotein and of catalase activity in 498 follicular fluid of obese women. Molecular Human Reproduction 16:117-124.

499

DOI: 10.1093/molehr/gap078

500

501

Benzie IF, Strain JJ. 1996. The ferric reducing ability of plasma (FRAP) as a measure of 502 "antioxidant power": The FRAP assay. Analytical Biochemistry 239:70-76.

503

DOI: 10.1006/abio.1996.0292

504

505

Boynton A, Neuhouser ML, Sorensen B, McTiernan A, Ulrich CM. 2008. Predictors of diet quality 506 among overweight and obese postmenopausal women. Journal of the American Dietetic 507 Association 108:125-130. DOI: 10.1016/j.jada.2007.10.037 
509 Brown LA, Kerr CJ, Whiting P, Finer N, McEneny J, Ashton T. 2012. Oxidant stress in healthy 510 normal-weight, overweight, and obese individuals. Obesity 17:460-466.

511 DOI: $10.1038 /$ oby.2008.590

512

513 Bunsawat K, Ranadive SM, Lane-Cordova AD, Yan H, Kappus RM, Fernhall B, Baynard T. 2017.

514 The effect of acute maximal exercise on postexercise hemodynamics and central arterial stiffness

515 in obese and normal-weight individuals. Physiological Reports 5:e13226.

516 DOI: $10.14814 /$ phy 2.13268

517

518 Cepeda-Lopez AC, Zimmermann MB, Wussler S, Melse-Boonstra A, Naef N, Mueller SM, Toigo 519 M, Herter-Aeberli I. 2019. Greater blood volume and Hb mass in obese women quantified by the 520 carbon monoxide-rebreathing method affects interpretation of iron biomarkers and iron 521 requirements. International Journal of Obesity 43:999-1008. DOI: 10.1038/s41366-018-0127-9

522

523 Ceriello A, Motz E. 2004. Is oxidative stress the pathogenic mechanism underlying insulin 524 resistance, diabetes, and cardiovascular disease? The common soil hypothesis 525 revisited. Arteriosclerosis, Thrombosis, and Vascular biology 24:816-823.

526 DOI: 10.1161/01.ATV.0000122852.22604.78

527

Chevion S, Berry EM, Kitrossky N, Kohen R. 1997. Evaluation of plasma low molecular weight antioxidant capacity by cyclic voltammetry. Free Radical Biology and Medicine 22:411-421.

530

DOI: 10.1016/S0891-5849(96)00337-1

531

Clarkson PM, Thompson HS. 2000. Antioxidants: What role do they play in physical activity and

health?. The American Journal of Clinical Nutrition 72:637S-646S. DOI: 10.1093/ajcn/72.2.637S

534

Clerk LH, Rattigan S, Clark MG. 2002. Lipid infusion impairs physiologic insulin-mediated

DOI: $10.2337 /$ diabetes.51.4.1138

538

Čolak E, Pap D, Nikolić L, Vicković, S. 2019. The impact of obesity to antioxidant defense 
543 Cole MA, Murray AJ, Cochlin LE, Heather LC, McAleese S, Knight NS, Sutton E, Abd Jamil A, 544 Parassol N, Clarke K. 2011. A high fat diet increases mitochondrial fatty acid oxidation and 545 uncoupling to decrease efficiency in rat heart. Basic Research in Cardiology 106:447-457.

546

547

548

549

550

551

552

553

554

555

556

557

558

559

560

561

562

563

564

565

566

567

568

569

570

571

572

573

574

575

576

DOI: $10.1007 / \mathrm{s} 00395-011-0156-1$

Collis T, Devereux RB, Roman MJ, De Simone G, Yeh JL, Howard BV, Fabsitz RR, Welty TK. 2001. Relations of stroke volume and cardiac output to body composition. Circulation 103:820825. DOI: 10.1161/01.CIR.103.6.820

Csige I, Ujvárosy D, Szabó Z, Lőrincz I, Paragh G, Harangi M, Somodi S. 2018. The impact of obesity on the cardiovascular system. Journal of Diabetes Research 2018:12.

DOI: $10.1155 / 2018 / 3407306$

Dasgupta, A., Klein, K., Dasgupta, A., \& Klein, K. 2014. Methods for measuring oxidative stress in the laboratory. Antioxidants in Food, Vitamins and Supplements Prevention and Treatment of Disease 2014:19-40. DOI: 10.1016/B978-0-12-405872-9.00002-1

Datta D, Normandin E, ZuWallack R. 2015. Cardiopulmonary exercise testing in the assessment of exertional dyspnea. Annals of Thoracic Medicine 10:77-86. DOI: 10.4103/1817-1737.151438

Dikalov S, Griendling KK, Harrison DG. 2007. Measurement of reactive oxygen species in cardiovascular studies. Hypertension 49:717-727. DOI:10.1161/01.HYP.0000258594.87211.6b

Doucet E, Almeras N, White MD, Despres JP, Bouchard C, Tremblay A. 1998. Dietary fat composition and human adiposity. European Journal of Clinical Nutrition 52:2-6.

DOI: $10.1038 /$ sj.ejcn.1600500

Ebong IA, Goff Jr DC, Rodriguez CJ, Chen H, Bertoni AG. 2014. Mechanisms of heart failure in obesity. Obesity Research \& Clinical Practice 8:e540-e548. DOI: 10.1016/j.orcp.2013.12.005

Ekkekakis P, Vazou S, Bixby WR, Georgiadis E. 2016. The mysterious case of the public health guideline that is (almost) entirely ignored: Call for a research agenda on the causes of the extreme avoidance of physical activity in obesity. Obesity Reviews 17:313-329.

DOI: $10.1111 /$ obr.12369 
578 Góth L. 1991. A simple method for determination of serum catalase activity and revision of

579 reference range. Clinica Chimica Acta 196:143-151. DOI: 10.1016/0009-8981(91)90067-M

580

581

Green S, O'Connor E, Kiely C, O'Shea D, Egana M. 2018. Effect of obesity on oxygen uptake and cardiovascular dynamics during whole-body and leg exercise in adult males and females. Physiological Reports 6:e13705. DOI: 10.14814/phy2.13705

584

585

586

587

588

589

590

591

592

593

594

595

596

597

598

599

600

601

602

603

604

605

606

607

608

609
Hadwan MH, Abed HN. 2016. Data supporting the spectrophotometric method for the estimation of catalase activity. Data in Brief 6:194-199. DOI: 10.1016/j.dib.2015.12.012

Hermsdorff HHM., Puchau B, Volp ACP, Barbos, KB, Bressan J, Zulet MÁ, Martínez JA.2011. Dietary total antioxidant capacity is inversely related to central adiposity as well as to metabolic and oxidative stress markers in healthy young adults. Nutrition \& Metabolism 8:59.

DOI: $10.1186 / 1743-7075-8-59$

Ho E, Galougahi KK, Liu CC, Bhindi R, \& Figtree GA. 2013. Biological markers of oxidative stress: Application to cardiovascular research and practice. Redox Biology 1:483-491.

DOI: 10.1016/j.redox.2013.07.006

Ighodaro OM, Akinloy, OA. 2018. First line defence antioxidants-superoxide dismutase (SOD), catalase (CAT) and glutathione peroxidase (GPX): Their fundamental role in the entire antioxidant defence grid. Alexandria Journal of Medicine 54:287-293. DOI: 10.1016/j.ajme.2017.09.001

Jankovica A, Korac A, Srdic-Galic B, Buzadzic B, Otasevic V, Stancic A, Vucetic M, Markelic M, Velickovic K, Golic I, Korac B. 2014. Differences in the redox status of human visceral and subcutaneous adipose tissues-relationships to obesity and metabolic risk. Metabolism 63:661-671. DOI: $10.1016 /$ j.metabol.2014.01.009

Jeeva JS, Sunitha J, Ananthalakshmi R, Rajkumari S, Ramesh M, Krishnan R. 2015. Enzymatic antioxidants and its role in oral diseases. Journal of Pharmacy \& BioAllied Sciences 7:S331.

DOI: $10.4103 / 0975-7406.163438$ 
610 Jung UJ, Choi MS. 2014. Obesity and its metabolic complications: The role of adipokines and the 611 relationship between obesity, inflammation, insulin resistance, dyslipidemia and nonalcoholic 612 fatty liver disease. International Journal of Molecular Sciences 15:6184-6223.

613 DOI: $10.3390 /$ ijms 15046184

614

615 Kanter R, Caballero B. 2012. Global gender disparities in obesity: A review. Advances in 616 Nutrition 3:491-498. DOI: 10.3945/an.112.002063

617

618 Kawasaki N, Asada R, Saito A, Kanemoto S, Imaizumi K. 2012. Obesity-induced endoplasmic 619 reticulum stress causes chronic inflammation in adipose tissue. Scientific Reports 2:799.

620 DOI: $10.1038 /$ srep00799

621

Kietzmann T, Görlach A. 2005. Reactive oxygen species in the control of hypoxia-inducible 623 factor-mediated gene expression. Seminars in Cell \& Developmental Biology 16:474-486.

624

DOI: $10.1016 /$ j.semcdb.2005.03.010

625

626

627

Laukkanen JA, Kurl S, Salonen JT, Lakka TA, Rauramaa R. 2006. Peak oxygen pulse during exercise as a predictor for coronary heart disease and all cause death. Heart 92:1219-1224.

628

DOI: $10.1136 /$ hrt.2005.077487

629 stress are present from an early age. PLOS ONE 13:e0191547.

DOI: 10.1371/journal.pone.0191547

634

Lim JU, Lee JH, Kim JS, Hwang YI, Kim TH, Lim SY, Yoo KH, Jung KS, Kim YK, Rhee CK. 2017. Comparison of World Health Organization and Asia-Pacific body mass index classifications 637 in COPD patients. International Journal of Chronic Obstructive Pulmonary Disease 12:2465638 2475. DOI: $10.2147 /$ COPD.S141295

639

640 Littleton SW. 2011. Impact of obesity on respiratory function. Respirology 17:43-49.

641 DOI: 10.1111/j.1440-1843.2011.02096.x

642 
643 Loftin M, Sothern M, Van Vrancken C, O'hanlon A, Udall J. 2003. Effect of obesity status on heart 644 rate peak in female youth. Clinical Pediatrics 42:505-510. DOI: 10.1177/000992280304200604

645

646 Lubkowska A, Dudzińska W, Bryczkowska I, Dołęgowska B. 2015. Body composition, lipid 647 profile, adipokine concentration, and antioxidant capacity changes during interventions to treat 648 overweight with exercise programme and whole-body cryostimulation. Oxidative Medicine and 649 Cellular Longevity 2015:13. DOI: 10.1155/2015/803197

650

Lubrano C, Valacchi G, Specchia P, Gnessi L, Rubanenko EP, Shuginina EA, Trukhanov AI, 652 Korkina LG, De Luca C. 2015. Integrated haematological profiles of redox status, lipid and inflammatory protein biomarkers in benign obesity and unhealthy obesity with metabolic

654 syndrome. Oxidative Medicine and Cellular Longevity 2015:14. DOI: 10.1155/2015/490613

655

656

657

Mafort TT, Rufino R, Costa CH, Lopes AJ. 2016. Obesity: Systemic and pulmonary complications, biochemical abnormalities, and impairment of lung function. Multidisciplinary

658 Respiratory Medicine 11:28. DOI: 10.1186/s40248-016-0066-z

659

660

Migliore L, Fontana I, Colognato R, Coppede F, Siciliano G, Murri, L. 2005. Searching for the 661 role and the most suitable biomarkers of oxidative stress in Alzheimer's disease and in other 662 neurodegenerative diseases. Neurobiology of Aging 26:587-595.

663

DOI: 10.1016/j.neurobiolaging.2004.10.002

664

Miller WM, Spring TJ, Zalesin KC, Kaeding KR, Janosz KEN, McCullough PA, Franklin BA. 666 2012. Lower than predicted resting metabolic rate is associated with severely impaired 667 cardiorespiratory fitness in obese individuals. Obesity 20:505-511. DOI: 10.1038/oby.2011.262

668

Myers J, McAuley P, Lavie CJ, Despres, JP, Arena R, Kokkinos P. 2015. Physical activity and cardiorespiratory fitness as major markers of cardiovascular risk: Their independent and interwoven importance to health status. Progress in Cardiovascular Diseases 57:306-314.

672

DOI: 10.1016/j.pcad.2014.09.011

673

674

Nimse SB, Pal D. 2015. Free radicals, natural antioxidants, and their reaction mechanisms. Royal 676 
677 Olechnowicz J, Tinkov A, Skalny A, Suliburska J. 2017. Zinc status is associated with 678 inflammation, oxidative stress, lipid, and glucose metabolism. The Journal of Physiological 679 Sciences 68:19-31. DOI: 10.1007/s12576-017-0571-7

680

681

682

Parameswaran K, Todd DC, Soth M. 2006. Altered respiratory physiology in obesity. Canadian Respiratory Journal 13:203-210. DOI: 10.1155/2006/834786

683

684

Pizzino G, Irrera N, Cucinotta M, Pallio G, Mannino F, Arcoraci V, Squadrito F, Altavilla D, Bitto

A. 2017. Oxidative stress: Harms and benefits for human health. Oxidative Medicine and Cellular 686 Longevity 2017:13. DOI: 10.1155/2017/8416763.

687

Poirier P, Giles TD, Bray GA, Hong Y, Stern JS, Pi-Sunyer FX, Eckel RH. 2006. Obesity and cardiovascular disease: Pathophysiology, evaluation, and effect of weight loss. Circulation 113:898-918. DOI: 10.1161/CIRCULATIONAHA.106.171016

691

692

693

Ramli NSF, Junit SM, Leong NK, Razali N, Jayapalan JJ, Aziz AA. 2017. Analyses of antioxidant status and nucleotide alterations in genes encoding antioxidant enzymes in patients with benign 694 and malignant thyroid disorders. PeerJ 5:e3365. DOI: 10.7717/peerj.3365

695

Re R, Pellegrini N, Proteggente A, Pannala A, Yang M, Rice-Evans C. 1999. Antioxidant activity Medicine 26:1231-1237. DOI: 10.1016//S0891-5849(98)00315-3

699

700

701

702

703

704

705

706

707

708

709

710

711

712

Rindler PM, Plafker SM, Szweda LI, Kinter M. 2013. High dietary fat selectively increases catalase expression within cardiac mitochondria. Journal of Biological Chemistry 288:1979-1990. DOI: $10.1074 /$ jbc.M112.412890

Rocha VZ, Libby P. 2009. Obesity, inflammation, and atherosclerosis. Nature Reviews Cardiology 6:399-409. DOI: $10.1038 /$ nrcardio.2009.55

Rössner, S.2002. Obesity: The disease of twenty-first century. International Journal of Obesity 26:S2-S4. DOI: 10.1038/sj.ijo.0802209

Salin K, Auer SK, Rey B, Selman C, Metcalfe NB. 2015. Variation in the link between oxygen consumption and ATP production, and its relevance for animal performance. Proceedings of the Royal Society B: Biological Sciences 282:20151028. DOI: 10.1098/rspb.2015.1028 
714 Sankhla M, Sharma TK, Mathur K, Rathor JS, Butolia V, Gadhok AK, Vardey SK, Sinha M,

715 Kaushik GG. 2012. Relationship of oxidative stress with obesity and its role in obesity induced

716 metabolic syndrome. Clinical Laboratory 58:385-392. PMID: 22783566

717

718

Savini I, Catani MV, Evangelista D, Gasperi V, Avigliano L. 2013. Obesity-associated oxidative stress: Strategies finalized to improve redox state. International Journal of Molecular Sciences 14:10497-10538. DOI: 10.3390/ijms140510497

721

722

723

Shim YM, Burnette A, Lucas S, Herring RC, Weltman J, Patrie JT, Weltman AL, Platts-Mills TA. 2013. Physical deconditioning as a cause of breathlessness among obese adolescents with a diagnosis of asthma. PLOS ONE 8:e61022. DOI: 10.1371/journal.pone.0061022

725

Singh S, Dulai PS, Zarrinpar A, Ramamoorthy S, Sandborn WJ. 2017. Obesity in IBD: Epidemiology, pathogenesis, disease course and treatment outcomes. Nature Reviews Gastroenterology \& Hepatology 14:110-121. DOI: 10.1038/nrgastro.2016.181

Soare A, Weiss EP, Holloszy JO, Fontana L. 2014. Multiple dietary supplements do not affect

Steinberg H, Baron A. 2002. Vascular function, insulin resistance and fatty acids. Diabetologia 45:623-634. DOI: 10.1007/s00125-002-0800-2 Journal of Clinical Investigation 100:1230-1239. DOI: 10.1172/JCI119636 Obesity-associated metabolic changes influence resting and peak heart rate in women and men.

Takken T, Blank AC, Hulzebos EH, Van Brussel M, Groen WG, Helders PJ. 2009. 745 Cardiopulmonary exercise testing in congenital heart disease: Equipment and test 746 protocols. Netherlands Heart Journal 17:339-344. DOI: 10.1007/BF03086280 
748 Tavora F, Zhang Y, Zhang M, Li L, Ripple M, Fowler D, Burke, A. 2012. Cardiomegaly is a 749 common arrhythmogenic substrate in adult sudden cardiac deaths, and is associated with obesity.

750 Pathology 44:187-191. DOI: 10.1097/PAT.0b013e3283513f54

751

752

753

Tinahones FJ, Murri-Pierri M, Garrido-Sánchez L, García-Almeida JM, García-Serrano S, García-Arnés J, García-Fuentes E. 2008. Oxidative stress in severely obese person is greater in

754 those with insulin resistance. Obesity 17:240-246. DOI: 10.1038/oby.2008.536

755

756

757

758

759

760

761

762

763

764

765

766

767

768

769

770

771

772

773

774

775

776

777

778

779

780

781

782

783

784
Torkanlou K, Bibak B, Abbaspour A, Abdi H, Moghaddam MS, Tayefi M, Mohammadzadeh E, Safarian BH, Aghasizade M, Ferns GA, Avan, A, Ghayour MM. 2016. Reduced serum levels of zinc and superoxide dismutase in obese individuals. Annals of Nutrition \& Metabolism 69:232236. DOI: $10.1159 / 000454894$

Van der Kooy K. 1992. Changes in fat-free mass in obese subjects after weight loss: A comparison of body composition measures. In: Van der Kooy K, Leenen R, Deurenberg P, Seidell JC, Westerterp KR, Hautvast JG, ed. Changes in body composition and fat distribution in response to weight loss and weight regain. International Journal of Obesity Related Metabolic Disorder, 16:675-683.

Van Gaal LF, Mertens IL, De Block CE. 2006. Mechanisms linking obesity with cardiovascular disease. Nature 444:875-880. DOI: 10.1038/nature05487

Via M. 2012. The malnutrition of obesity: Micronutrient deficiencies that promote obesity. International Scholarly Research Network Endocrinology 2012:8. DOI: 10.5402/2012/103472

Wang X, Hai C. 2015. Redox modulation of adipocyte differentiation: Hypothesis of "Redox Chain" and novel insights into intervention of adipogenesis and obesity. Free Radical Biology and Medicine 89:99-125. DOI: 10.1016/j.freeradbiomed.2015.07.012

Williams SM, Eleftheriadou A, Alam U, Cuthbertson DJ, Wilding JP. 2019. Cardiac autonomic neuropathy in obesity, the metabolic syndrome and prediabetes: A narrative review. Diabetes Therapy 2019:1-27. DOI: 10.1007/s13300-019-00705-z.

Yesilbursa D, Serdar Z, Serdar A, Sarac M, Coskun S, Jale C. 2004. Lipid peroxides in obese patients and effects of weight loss with orlistat on lipid peroxides levels. International Journal of Obesity 29:142-145. DOI: 10.1038/sj.ijo.0802794 
785 Yudkin JS, Kumari M, Humphries SE, Mohamed-Ali V. 2000. Inflammation, obesity, stress and 786 coronary heart disease: Is interleukin-6 the link?. Atherosclerosis 148:209-214.

787 DOI: 10.1016/S0021-9150(99)00463-3

788

789 Zhang R, Liu R, Zong W. 2016. Bisphenol S interacts with catalase and induces oxidative stress 790 in mouse liver and renal cells. Journal of Agricultural and Food Chemistry 64:6630-6640.

791 DOI: 10.1021/acs.jafc.6b02656 


\section{Table 1 (on next page)}

Table 1: Characteristics of the study subjects. 
Table 1: Characteristics of the study subjects.

\begin{tabular}{l|c|c|c|c}
\hline & $\begin{array}{c}\text { Normal weight } \\
(\boldsymbol{n}=\mathbf{2 3})\end{array}$ & $\begin{array}{c}\text { Overweight } \\
(\boldsymbol{n}=\mathbf{2 8})\end{array}$ & $\begin{array}{c}\text { Obese } \\
(\boldsymbol{n}=\mathbf{2 9})\end{array}$ & $p$ value \\
\hline Age (years) & $25(20,31)$ & $33(25,42)$ & $35(32,42)$ & $<0.001^{*}$ \\
\hline Height $(\mathrm{cm})$ & $155.35 \pm 5.47$ & $154.86 \pm 6.29$ & $154.60 \pm 4.63$ & 0.89 \\
\hline Weight $(\mathrm{kg})$ & $49.19 \pm 4.60$ & $60.46 \pm 6.12$ & $74.40 \pm 9.45$ & $<0.001^{*}$ \\
\hline BMI $\left(\mathrm{kg} / \mathrm{m}^{2}\right)$ & $20.40 \pm 1.63$ & $25.17 \pm 1.32$ & $31.07 \pm 3.18$ & $<0.001^{*}$ \\
\hline WHR $\$$ & $0.81(0.78,0.85)$ & $0.88^{\mathrm{c}}(0.84,0.90)$ & $0.91^{\mathrm{a}}(0.86,0.96)$ & $<0.001^{*}$ \\
\hline PBF $(\%)$ & $30.17 \pm 5.23$ & $37.91^{\mathrm{c}} \pm 5.80$ & $44.01^{\mathrm{a}, \mathrm{b}} \pm 4.75$ & $<0.001^{*}$ \\
\hline BFM (kg) & $14.93 \pm 3.24$ & $22.73^{\mathrm{c}} \pm 4.51$ & $32.99^{\mathrm{a}, \mathrm{b}} \pm 6.92$ & $<0.001^{*}$ \\
\hline SMM (kg) & $18.33 \pm 2.19$ & $20.37^{\mathrm{c}} \pm 3.39$ & $22.54^{\mathrm{a}, \mathrm{b}} \pm 2.64$ & $<0.001^{*}$ \\
\hline
\end{tabular}

\$ indicates data is presented as median $\left(25^{\text {th }}, 75^{\text {th }}\right.$ percentiles); Data for others are presented as mean \pm standard deviation. BMI, Body mass index; WHR, Waist-hip ratio; PBF, Percentage body fat; BFM, Body fat mass; SMM, Skeletal muscle mass. ${ }^{a}$ indicates significant difference between obese and normal weight groups. ${ }^{\mathbf{b}}$ indicates significant difference between obese and overweight groups. ${ }^{c}$ indicates significant difference between overweight and normal weight groups. * indicates significant difference at $p<0.05$. 
Table 2 (on next page)

Table 2: Cardiopulmonary exercise testing (CPET) analyses. 
1 Table 2: Cardiopulmonary exercise testing (CPET) analyses.

\begin{tabular}{|c|c|c|c|c|c|}
\hline & $\begin{array}{l}\text { Normal weight } \\
(n=23)\end{array}$ & $\begin{array}{l}\text { Overweight } \\
(n=28)\end{array}$ & $\begin{array}{l}\text { Obese } \\
(n=29)\end{array}$ & $\begin{array}{l}F \text { or } x^{2} \\
\text { value }\end{array}$ & $\begin{array}{c}p \\
\text { value }\end{array}$ \\
\hline $\begin{array}{l}\text { Exercise duration } \\
\text { (min) }\end{array}$ & $10.07 \pm 2.27$ & $9.13 \pm 2.26$ & $9.07 \pm 1.30$ & 1.95 & 0.15 \\
\hline $\begin{array}{l}\text { Peak oxygen } \\
\text { consumption } \\
(\mathrm{ml} / \mathrm{kg} / \mathrm{min})^{\$}\end{array}$ & $\begin{array}{c}25.18 \\
(23.39,27.84)\end{array}$ & $\begin{array}{c}22.53 \\
(20.01,26.45)\end{array}$ & $\begin{array}{c}19.14^{\mathrm{a}, \mathrm{b}} \\
(17.25,21.64)\end{array}$ & 24.60 & $<0.001^{*}$ \\
\hline Metabolic equivalents \$ & $\begin{array}{c}6.90 \\
(6.20,8.00)\end{array}$ & $\begin{array}{c}6.35 \\
(5.60,7.60)\end{array}$ & $\begin{array}{c}5.30^{\mathbf{a}, \mathbf{b}} \\
(5.10,5.90)\end{array}$ & 22.76 & $<0.001^{*}$ \\
\hline Respiratory exchange ratio & $1.26 \pm 0.09$ & $1.22 \pm 0.10$ & $1.22 \pm 0.11$ & 1.28 & 0.29 \\
\hline $\begin{array}{l}\text { Minute ventilation } \\
\text { (L/min) }\end{array}$ & $46.96 \pm 11.11$ & $51.84 \pm 11.61$ & $50.97 \pm 8.71$ & 1.52 & 0.23 \\
\hline $\begin{array}{l}\text { Breathing rate } \\
\text { (breath/min) }\end{array}$ & $57.04 \pm 10.12$ & $52.43 \pm 8.15$ & $52.69 \pm 8.97$ & 2.02 & 0.14 \\
\hline $\begin{array}{l}\text { Ventilatory tidal volume } \\
(\mathrm{ml} / \mathrm{kg})\end{array}$ & $1.01 \pm 0.19$ & $1.16 \pm 0.22$ & $1.14 \pm 0.26$ & 2.90 & 0.06 \\
\hline Respiratory frequency & $46.37 \pm 7.26$ & $44.43 \pm 7.65$ & $46.18 \pm 9.53$ & 0.45 & 0.64 \\
\hline $\begin{array}{l}\text { Peak heart rate } \\
\text { (beats/min) }\end{array}$ & $173.22 \pm 9.94$ & $166.04 \pm 14.00$ & $165.70 \pm 8.71$ & 3.48 & $0.04^{*}$ \\
\hline $\begin{array}{l}\text { Oxygen pulse } \\
\text { (mL/beat) }\end{array}$ & $7.08 \pm 1.40$ & $8.75^{c} \pm 1.72$ & $8.53^{a} \pm 1.69$ & 7.70 & $<0.001^{*}$ \\
\hline Cardiac output & $7.66 \pm 1.57$ & $8.59 \pm 1.45$ & $8.53 \pm 1.54$ & 2.90 & 0.06 \\
\hline $\begin{array}{l}\text { Partial pressure of } \\
\text { end-tidal carbon dioxide } \\
(\mathrm{mmHg})\end{array}$ & $36.91 \pm 4.03$ & $37.11 \pm 4.67$ & $37.41 \pm 3.95$ & 0.09 & 0.91 \\
\hline $\begin{array}{l}\text { Partial pressure of } \\
\text { end-tidal oxygen } \\
(\mathrm{mmHg})\end{array}$ & $114.09 \pm 5.11$ & $114.14 \pm 5.08$ & $113.86 \pm 5.05$ & 0.02 & 0.98 \\
\hline $\begin{array}{l}\text { Ventilatory equivalent } \\
\text { of carbon dioxide } \$\end{array}$ & $\begin{array}{c}31.20 \\
(29.75,34.15)\end{array}$ & $\begin{array}{c}31.15 \\
(29.05,34.30)\end{array}$ & $\begin{array}{c}31.20 \\
(28.50,35.20)\end{array}$ & 0.05 & 0.98 \\
\hline $\begin{array}{l}\text { Ventilatory equivalent } \\
\text { of oxygen } \$\end{array}$ & $\begin{array}{c}37.05 \\
(35.60,42.80)\end{array}$ & $\begin{array}{c}36.20 \\
(33.05,41.60)\end{array}$ & $\begin{array}{c}36.40 \\
(32.90,42.60)\end{array}$ & 0.32 & 0.85 \\
\hline
\end{tabular}

\$ indicates data is presented as median $\left(25^{\text {th }}, 75^{\text {th }}\right.$ percentiles); Data for others are presented as mean \pm standard deviation. ${ }^{a}$ indicates significant difference between obese and normal weight groups. ${ }^{\mathbf{b}}$ indicates significant difference between obese and overweight groups. ${ }^{c}$ indicates significant difference between overweight and normal weight groups. * indicates significant difference at $p<0.05$. 


\section{Table $\mathbf{3}$ (on next page)}

Correlation analyses between biochemical and CPET parameters. 
1 Table 3: Correlation analyses between biochemical and CPET parameters.

\begin{tabular}{|c|c|c|c|c|c|c|c|}
\hline & ABTS & FRAP & ROS $^{\$}$ & MDA & CAT & GPx & SOD \\
\hline Exercise duration & -0.146 & -0.195 & 0.141 & $-0.263^{*}$ & -0.237 & -0.008 & -0.043 \\
\hline $\begin{array}{l}\text { Peak oxygen } \\
\text { Consumption } \$\end{array}$ & 0.00 & 0.064 & -0.08 & -0.169 & $-0.251^{*}$ & 0.021 & 0.002 \\
\hline Metabolic equivalents \$ & -0.036 & 0.109 & 0.031 & -0.185 & -0.157 & 0.015 & -0.01 \\
\hline $\begin{array}{l}\text { Respiratory exchange } \\
\text { ratio }\end{array}$ & 0.126 & -0.008 & 0.144 & -0.027 & 0.006 & 0.151 & 0.046 \\
\hline Minute ventilation & -0.126 & -0.062 & -0.014 & -0.056 & -0.029 & 0.083 & -0.091 \\
\hline Breathing rate & 0.121 & 0.057 & 0.049 & -0.019 & 0.022 & -0.136 & 0.146 \\
\hline Ventilatory tidal volume & 0.022 & -0.057 & -0.023 & -0.055 & -0.026 & -0.034 & 0.058 \\
\hline Respiratory frequency & -0.139 & -0.057 & 0.033 & -0.023 & 0.034 & 0.165 & -0.187 \\
\hline Heart rate peak & 0.057 & 0.07 & -0.065 & -0.023 & -0.049 & -0.095 & -0.098 \\
\hline Oxygen pulse & $-0.253^{*}$ & -0.166 & -0.165 & -0.039 & 0.04 & 0.025 & -0.084 \\
\hline Cardiac output & $-0.252^{*}$ & -0.132 & -0.065 & -0.099 & -0.078 & 0.04 & -0.125 \\
\hline $\begin{array}{l}\text { Partial pressure end- } \\
\text { tidal carbon dioxide }\end{array}$ & -0.078 & -0.016 & 0.097 & -0.04 & -0.093 & -0.035 & -0.07 \\
\hline $\begin{array}{l}\text { Partial pressure end- } \\
\text { tidal oxygen }\end{array}$ & 0.112 & 0.049 & -0.022 & 0.091 & 0.047 & 0.097 & 0.039 \\
\hline $\begin{array}{l}\text { Ventilatory equivalent of } \\
\text { carbon dioxide } \$\end{array}$ & 0.064 & 0.026 & -0.057 & 0.023 & 0.019 & 0.004 & 0.042 \\
\hline $\begin{array}{l}\text { Ventilatory equivalent of } \\
\text { oxygen } \$\end{array}$ & 0.084 & -0.039 & -0.009 & 0.041 & -0.028 & 0.048 & 0.028 \\
\hline
\end{tabular}

\$indicates non-distributed data and analysed using Spearman's correlation analyses; Other data is normally 3 distributed and analysed using Pearson's correlation analyses; Data is presented as correlation coefficients 4 (r); ABTS, ABTS radical scavenging activity; FRAP, Ferric reducing ability of plasma; ROS, Reactive 5 oxygen species; MDA, Malondialdehyde; CAT, Catalase activity; GPx, Glutathione peroxidase activity; 6 SOD, Superoxide dismutase activity; * indicates the correlation is significant at the 0.05 level (2-tailed). 


\section{Table 4 (on next page)}

Pearson's partial correlation analyses between biochemical and CPET parameters (age control) 
1 Table 4: Partial correlation analyses between biochemical and CPET parameters (age control)

\begin{tabular}{l|c|c|c|c|c|c}
\hline & ABTS & FRAP & MDA & CAT & GPx & SOD \\
\hline Exercise duration & -0.14 & -0.18 & -0.22 & -0.18 & 0.00 & -0.10 \\
\hline $\begin{array}{l}\text { Respiratory exchange } \\
\text { ratio }\end{array}$ & 0.13 & 0.00 & -0.02 & 0.02 & 0.15 & 0.04 \\
\hline Minute ventilation & -0.12 & -0.06 & -0.04 & -0.01 & 0.09 & -0.11 \\
\hline Breathing rate & 0.13 & 0.06 & 0.00 & 0.05 & -0.13 & 0.13 \\
\hline $\begin{array}{l}\text { Ventilatory tidal volume } \\
\text { Respiratory frequency }\end{array}$ & -0.02 & -0.07 & -0.09 & -0.06 & -0.04 & 0.09 \\
\hline Heart rate peak & 0.08 & -0.12 & 0.09 & 0.08 & -0.10 & -0.21 \\
\hline $\begin{array}{l}\text { Oxygen pulse } \\
\text { Cardiac output }\end{array}$ & $\mathbf{- 0 . 2 6 *}$ & -0.18 & -0.07 & 0.00 & 0.02 & -0.06 \\
\hline $\begin{array}{l}\text { Partial pressure end-tidal } \\
\text { carbon dioxide }\end{array}$ & -0.08 & -0.01 & -0.03 & -0.09 & -0.03 & -0.08 \\
\hline $\begin{array}{l}\text { Partial pressure end-tidal } \\
\text { oxygen }\end{array}$ & 0.11 & 0.05 & 0.08 & 0.04 & 0.10 & 0.05 \\
\hline \begin{tabular}{l} 
Partia cortelation \\
\hline
\end{tabular} & -0.12 & -0.07 & -0.05 & 0.04 & -0.15 \\
\hline
\end{tabular}

2 Partial correlation test was only done on normally-distributed data. Since peak oxygen consumption, 3 metabolic equivalents, ventilatory equivalent of oxygen and carbon dioxide as well as reactive oxygen 4 species were not normally distributed, these data are not included here. Data is presented as correlation 5 coefficients (r); ABTS, ABTS radical scavenging activity; FRAP, Ferric reducing ability of plasma; 6 MDA, Malondialdehyde; CAT, Catalase activity; GPx, Glutathione peroxidase activity; SOD, Superoxide 7 dismutase activity; * indicates the correlation is significant at the 0.05 level (2-tailed). 


\section{Figure 1}

\section{Biochemical analyses of plasma.}

1(a) : ABTS radical scavenging activity, expressed as Trolox Equivalent Antioxidant Activity (TEAC); 1(b): Ferric reducing activity of plasma (FRAP) activity; $\mathbf{1}(\mathbf{c})$ : Reactive oxygen species (ROS) analysis, $\mathbf{1}(\mathbf{d})$ : Lipid peroxidation analysis, measured as malondialdehyde (MDA) level, $\mathbf{1}(\mathbf{e})$ : Catalase (CAT) activity; $\mathbf{1}(\mathbf{f})$ : Glutathione peroxidase (GPx) activity; $\mathbf{1}(\mathbf{g})$ : Superoxide dismutase (SOD) activity. ${ }^{\$}$ Data for ROS analysis is presented as median and error bar represents $25^{\text {th }}, 75^{\text {th }}$ percentiles; Data for others are presented as mean and error bar represents standard deviation. * indicates significant difference between overweight and normal weight groups. ** indicates significant difference between obese and normal weight groups. \# indicates significant difference between obese and overweight groups. The significant level was set at $p<$ 0.05 . 

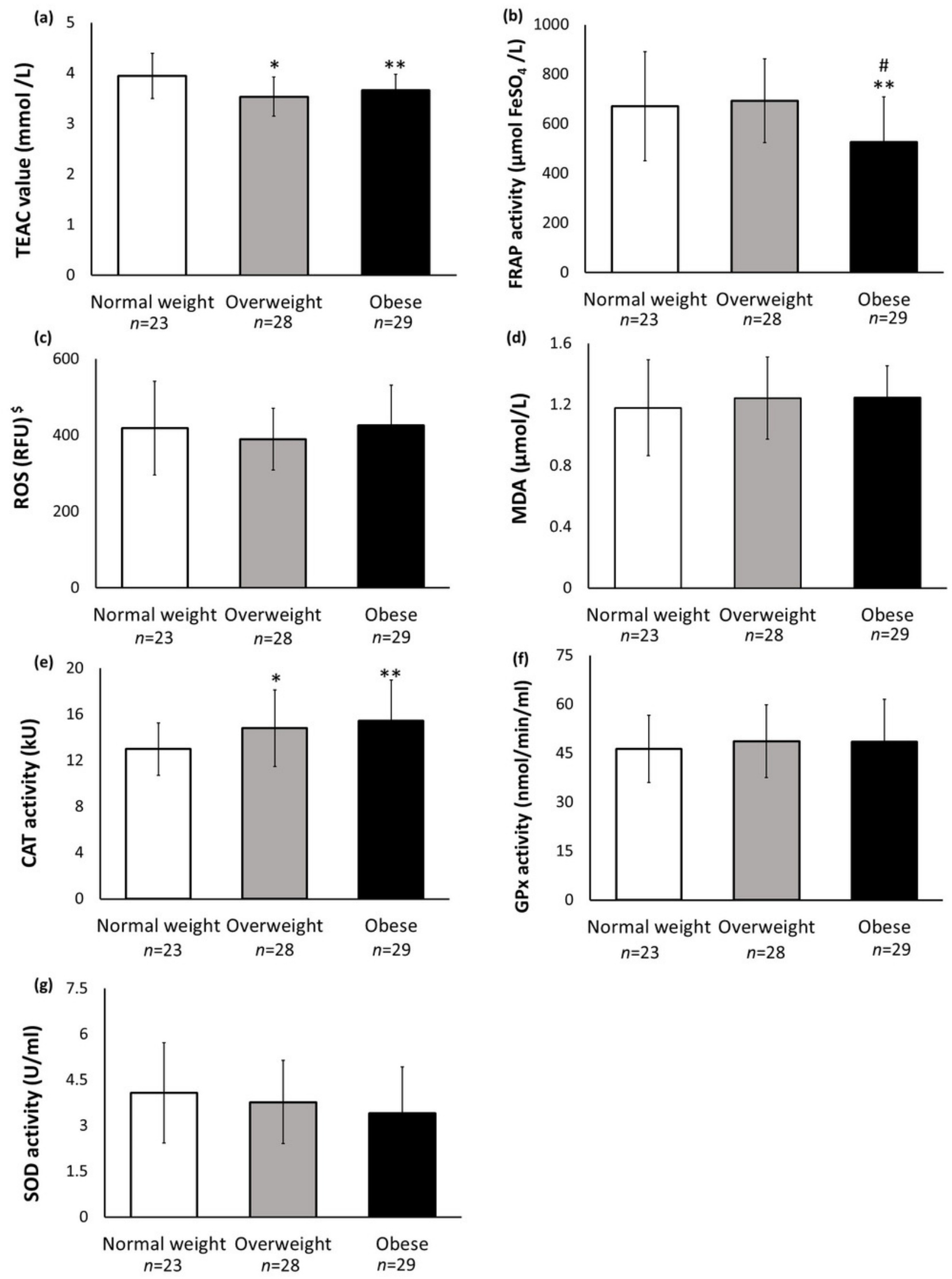